\title{
The Medical Treatment of the Hypersecreting Pituitary Gland
}

\author{
Bernard Corenblum
}

\begin{abstract}
Pituitary adenomas may produce local endocrine and neurological effects, as well as systemic metabolic complications due to hormonal hypersecretion. Medical therapy with pharmacological agents has been developed and is based on the neurotransmitter regulation of normal pituitary hormonal secretion. 189 patients with secretory pituitary adenomas underwent medical therapy for the hypersecretory state. 156 of these were prolactin-secreting adenomas, 16 of which were in males. The response of bromocriptine was almost universal with lowering of serum prolactin and reversal of the clinical symptoms, as well as tumor shrinkage of most large adenomas with suprasellar extension. 23 patients with acromegaly were treated with bromocriptine, with 11 noting clinical improvement, and decreased tumor size in two. Five patients with Cushing's disease were treated with cyproheptadine, with only one showing a biochemical and clinical improvement. Two patients with Nelson's syndrome each had progressive tumor growth stabilized with cyproheptadine and bromocriptine in one, and sodium valproate in the other. There appears to be a role for medical therapy in the majority of prolactin-secreting pituitary tumors, some growth hormone secreting pituitary tumors, and selected adrenocorticotropin secreting-pituitary tumors.
\end{abstract}

RÉSUMÉ: Traitement médical de la glande pituitaire hypersécrétrice Les adénomes pituitaires peuvent produire des effets locaux endocriniens et neurologiques ainsi que des complications métaboliques systémiques dues àl'hypersécrétion hormonale. Une approche thérapeutique a été développée, basée sur la régulation par les neurotransmetteurs de la sécrétion pituitaire hormonale normale. 189 patients avec adénomes pituitaire sécrétants out reçu un traitement médical de leur état hypersécrétoire. Dans $156 \mathrm{cas}$, il s'agissait d'adénomes sécrétant la prolactine dont $16 \mathrm{chez}$ des mâles. La réponse à la bromocriptine est presque uniforme avec chute de la prolactine sérique et renversement des symptômes cliniques. Il y eut aussi un rapetissement des tumeurs, surtout des gros adénomes avec extension suprasellaire. 23 patients avec acromégalie furent traités à la bromocriptine. Il notèrent une amélioration clinique et chez 2, la tumeur a diminué de grosseur. Cinq cas de maladie de Cushing furent traités à la cyproheptadine, un seul montant une amélioration biochimique et clinique. Une tumeur progressive s'est vue stabilisée dans sa croissance chez 2 cas de maladie de Nelson, l'un avec la cyproheptadine et la bromocriptine, l'autre avec le valproate de sodium. Il semble donc y avoir une approche médicale possible dans le traitement de la majorité des tumeurs pituitaires sécrétant la prolactine, pour certaines tumeurs pituitaires sécrétant l'hormone de croissance et pour quelques rares tumeurs sécrétant l'adrénocorticotropine.

Can. J. Neurol. Sci. 1985: 12:243-250

Pituitary tumors are usually considered to account for approximately $10 \%$ of clinically obvious intracranial neoplasms. This may be an underestimate. The incidence of pituitary adenomas at routine autopsy may vary from under $10 \%$ to $25 \%$ (Costello 1936; Burrow et al 1981). There have been diagnostic advances in modern endocrinology due to the development of the radioimmunoassay, thus allowing earlier and more sensitive detection of secretory pituitary adenomas, as well as the discovery of prolactin as a distinct hormone in humans. Furthermore, there have been advances in radiological diagnostic techniques, neurosurgical techniques, and the development of neuroendocrine pharmacological agents, especially the dopamine agonists. This has allowed the clinical diagnosis of pituitary adenomas to be made with increased frequency.

Pituitary adenomas usually consist of discrete histological demarcations from the normal pituitary gland. It is not possible to predict the growth potential of any given adenoma, once it is detected. The high post-mortem incidence of pituitary adenomas suggests that the majority remain subclinical. The adenomas may be contained within the sella, although less commonly may invade surrounding brain, bone, or sinuses. The local extension will affect the success of surgical removal. Pituitary adenomas may produce both local and peripheral changes. There may be compression of neural and/or bony structures, compression of

From the Department of Medicine, Faculty of Medicine, The University of Calgary

Received December 11, 1984

Reprint requests to: Dr. B. Corenblum, Room 1412, Health Sciences Centre, 3330 Hospital Drive N.W., Calgary, Alberta T2N 4N I 
normal pituitary tissue resulting in partial or total hypopituitarism, compression of the cavernous sinus with involvement of cranial nerves, compression of the optic chiasm, and obstruction of the third ventricle. Furthermore, the adenoma may secrete one, but occasionally more than one, pituitary hormone with its resultant metabolic and clinical effects.

Ideal therapy would be ablation of the tumor with the surrounding pituitary and neural structures left intact. Surgical results may vary inversely with the size of the tumor. Longterm results are now becoming available, and it appears that even clinical cures with surgery may have a significant recurrence rate within the subsequent ten years (Serri et al 1983). Conventional pituitary irradiation has a low morbidity rate, but has problems of long latency between the treatment and arrest of the tumor, and some unpredictability of response. There appears to be a general arrest of growth, and should any subsequent cure occur, generally this is evident five to ten years after the treatment. Recent evaluation has shown a high percentage of pituitary insufficiency, either partial or total, within ten years of the irradiation therapy. The high energy heavy particle irradiation appears to have a similar pattern without the long latency between treatment and arrest of the tumor, but this is available in only two centres in North America.

Medical therapy with pharmacological agents has been tried for many years, since most pituitary adenomas are not completely autonomous. They may respond to similar suppression and/or stimulation agents as seen in normal subjects, but the response may be quantitatively or qualitatively different. The pharmacological therapy is based on the neurotransmitter regulation of the normal pituitary. The utilization of neuropharmacological agents to alter hormone secretion has been demonstrated to selectively control the metabolic effects and clinical signs of hormonal hypersecretion from selected pituitary tumors. Recent observations have also demonstrated a control of progressive tumor growth, and a demonstrable regression of tumor size in some cases, especially common with large prolactin secreting pituitary tumors (Corenblum and Hanley 1981). Although longterm follow-up for most of the neuropharmacological agents has yet to be observed, prolonged utilization of bromocriptine for prolactin secreting pituitary adenomas has been reported, without any serious long-term cumulative problems (Corenblum and Taylor 1983).

The neurotransmitter control of normal pituitary secretion is not clearly delineated, and the interaction is complex. Prolactin appears to be mainly under inhibitory control, with dopamine having a direct physiological role, although factors other than dopamine inhibit prolactin secretion. Several peptides have been found to facilitate the release of prolactin, but the neurotransmitter serotonin may have a role. These observations have led to the clinical use of dopamine agonists, such as bromocriptine, and serotonin antagonists, such a metergoline for the treatment of prolactin-secreting pituitary adenomas.

The control of growth hormone secretion is complex, with both releasing and inhibiting peptides being characterized. In normal subjects growth hormone appears to be stimulated by dopamine, norepinephrine, acetylcholine, and serotonin agonists. In acromegaly, there appears to be a paradoxical fall of growth hormone in response to dopamine agonists (Chiodini et al 1974). Such a response has allowed dopamine agonists to be used for the treatment of growth hormone secreting pituitary tumors.
ACTH is primarily controlled by the recently described peptide corticotropin releasing hormone. The most important neurotransmitter effects appear to be by the catecholamines and serotonin. Serotonin facilitates ACTH release, possibly via a cholinergic interneuron (Jones et al 1981). The endogenous opioids also appear to be important, likely inhibitory in nature (Stubbs et al 1978). Other roles for control have been reported for acetycholine, melatonin, and gamma aminobutyric acid (GABA). All stimulatory and inhibitory effects and their sites of action are not well understood. These observations have led to clinical trials for ACTH secreting pituitary adenomas with the antiserotoninergic and anticholinergic drug cyproheptadine,the dopamine agonist bromocriptine, and the GABA agonist sodium valproate.

This is a report of the treatment of hypersecretory pituitary adenomas with various neuropharmacologic agents over a ten year period.

\section{Materials ANd MethodS}

A total of 189 patients with secretory pituitary adenomas underwent medical therapy for the hypersecretory state (Table I). Prolactin secreting pituitary adenomas made up 156 of the subjects. 151 were treated with bromocriptine in dosage varying from $1.25-7.5 \mathrm{mg}$ per day, and 89 have had continuous therapy under medical supervision for 5 - 10 years, as previously reported in part (Corenblum and Taylor 1983). Five were treated with pergolide. Indices of response included normalization of serum prolactin, return of menses, fertility, loss of galactorrhea in the females, and improved libido and normalization of serum testosterone in males. Tumor size was evaluated initially with pneumoencephalography, but for the past seven years by computerized tomography scanning. Any visualized tumor had its size monitored by repeated radiological evaluation as well as indirectly by visual field testing and pituitary reserve testing. Pituitary reserve was tested in response to insulin-induced hypoglycemia, TRH, and GnRH (Corenblum 1979). None of these patients had surgical or irradiation therapy prior to the onset of bromocriptine and pergolide therapy.

Twenty-six patients presented with acromegaly, 16 females and 10 males. All were treated with bromocriptine in dosages varying from $10-20 \mathrm{mg} /$ day in four divided doses. Growth hormone secretion was assessed following glucose administration, the clinical response was assessed depending on the presenting symptoms and hand volume measurement, and tumor size changes were followed with repeated CT scanning. Six of these patients had concomitant hypersecretion of prolactin. Seventeen of 26 patients had previously undergone surgical and/or irradiation therapy for the acromegaly without clinical or biochemical cure, while nine were treated initially with bromocriptine. In 13 patients demonstrating clinical improvement, nine of the 13 subsequently subsequently underwent conventional pituitary irradiation therapy with maintenance of bromocriptine therapy, while four have remained on bromocriptine alone. All bromocriptine failures underwent irradiation therapy.

Seven patients presented with ACTH secreting pituitary adenomas. Five had Cushing's disease, and were initially treated with cyproheptadine $24 \mathrm{mg} /$ day for a minimum of three months. None of these patients had previous surgical or irradiation therapy, but four of the five subsequently underwent transphenoidal resection of the underlying pituitary adenoma. Two 
Table 1: 189 Patients With Demonstrated or Presumed Pituitary Adenomas Undergoing Medical Therapy

\begin{tabular}{|c|c|c|c|c|}
\hline Prolactinoma & 156 & $140 / 16$ & None & $\begin{array}{l}151 \text { Bromocriptine } \\
5 \text { Pergolide }\end{array}$ \\
\hline Acromegaly & 26 & $16 / 10$ & $\begin{array}{l}9 \text { None } \\
10 \text { Surgery } \\
4 \text { Surgery + } \\
\text { Irradiation } \\
3 \text { Irradiation }\end{array}$ & Bromocriptine \\
\hline Cushing's disease & 5 & $4 / 1$ & None & Cyproheptadine \\
\hline \multirow[t]{2}{*}{ Nelson's syndrome } & 2 & $2 / 0$ & Surgery & $\begin{array}{l}\text { Cyproheptadine }+ \\
\text { Bromocriptine }\end{array}$ \\
\hline & & & $\begin{array}{l}\text { Surgery + } \\
\text { Irradiation }\end{array}$ & Sodium Valproate \\
\hline
\end{tabular}

patients presented with Nelson's syndrome, eight and 17 years following bilateral adrenalectomy. One had pituitary irradiation five years following the adrenalectomy, once the onset of hyperpigmentation was noted. This patient had one attempted surgical removal, and after this failed was treated with cyproheptadine, $24 \mathrm{mg} /$ day, and bromocriptine $5 \mathrm{mg} / \mathrm{day}$. The second patient had irradiation and then two surgical attempts for removal, yet continued to demonstrate an invasive ACTH secreting adenoma. She was then treated with sodium valproate, 400 $\mathrm{mg} / \mathrm{day}$.

\section{RESULTS}

The 156 patients with prolactin secreting pituitary adenomas consisted of 140 women and 16 men, varying from age 15 to 46 . The 140 women were divided into three groups, depending on the size of the tumor (Table 2). Twenty-one were classified with macroadenomas according to gross enlargement of the sella turcica and the adenoma being at least $1 \mathrm{~cm}$ in size as assessed by radiological visualization. The 78 women with microadenomas had distortion of sellar shape or normal sella turcicas, but CT scan demonstrated an adenoma less than $1 \mathrm{~cm}$ in size. The 41 classified with normal sellas had no radiological abnormality detected, but the clinical diagnosis was of a prolactin secreting pituitary tumor on the basis of clinical impression, exclusion of other causes of hyperprolactinemia, and failure to demonstrate any release of prolactin in response to an injection of thyrotropin releasing hormone (Corenblum 1979). The patients with macroadenomas included three presenting with primary amenorrhea. Mass signs were clinically evident in eight patients with macroadenomas, all with visual field abnormalities, and seven of these with headaches. Of these eleven, six had normal pituitary reserve to stimulatory testing. Of the six with normal pituitary reserve, all six had return of menses, and of four desirous of pregnancy, two did conceive. Of the five with some degree of abnormal pituitary reserve, three of the five had return of menses, and none were desirous of pregnancy. Ten patients did not have any clinical signs of an underlying mass. Seven of these had normal pituitary reserve to stimulatory testing, all seven had return of menses, and of the five desirous of pregnancy, three did conceive. The three with abnormal pituitary reserve had two of the three return to normal menstrual activity, and none were desirous of pregnancy. In these 21 patients the tumor was clearly visualized, and tumor regression was noted in seventeen of the twenty-one. Eleven of them no longer had any suprasellar extension that was previously present. Abnormal visual fields were documented in eight, with seven returning to normal. The other did not fully return to normal, despite the fact that the tumor had regressed. Of the eight patients with abnormal pituitary reserve, six of the eight had normalization

Table 2: Response of 140 Women With Prolactinomas to Medical Therapy

A. Macroadenomas $(n=21)$

Normalization visual field abnormalities $7(8)^{*}$

Decrease in tumor size 17

Loss of headaches $11(14)$

Clinical improvement 21

Normal pituitary reserve 13

(13 return of menses; $2 / 4$ pregnant)

Abnormal pituitary reserve 8

( 5 return of menses; 6 return to normal pituitary reserve)

B. Microadenomas $(\mathrm{n}=78)$

Normal pituitary reserve 76

(74 return of menses, $34 / 39$ pregnant)

Abnormal pituitary reserve 2

( 1 return of menses, $1 / 2$ pregnant)

C. Normal Sellas $(n=41)$

Normal pituitary reserve 40

(40 return of menses, $24 / 28$ pregnant)

Abnormal pituitary reserve 1 ( 0 menses)

D. Total $(n=140)$

Normal pituitary reserve 129

(127 return of menses; $60 / 71$ pregnant)

Abnormal pituitary reserve 11

(6 return of menses; $1 / 2$ pregnant)

* Figure in brackets indicates number of patients with this symptom. 
of pituitary reserve within six months of therapy with bromocriptine.

The 78 women with microadenomas included 76 with normal pituitary reserve, and 74 of these 76 had normal return of menses. Of 39 desirous of pregnancy, 34 did conceive. Two patients with abnormal pituitary reserve included one who did have return of menses and became pregnant, and the other

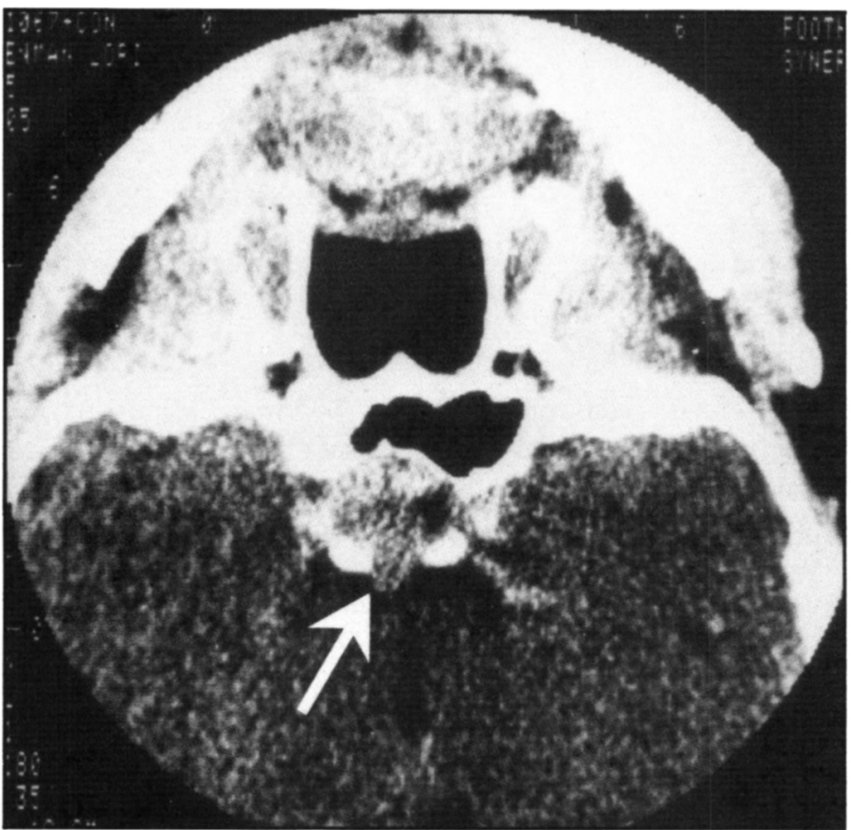

Figure la - CT scan of 17 year old woman with primary amenorrhea, demonstrating a large intrasellar mass with suprasellar extension. Serum prolactin was 50 times the upper limit of normal.

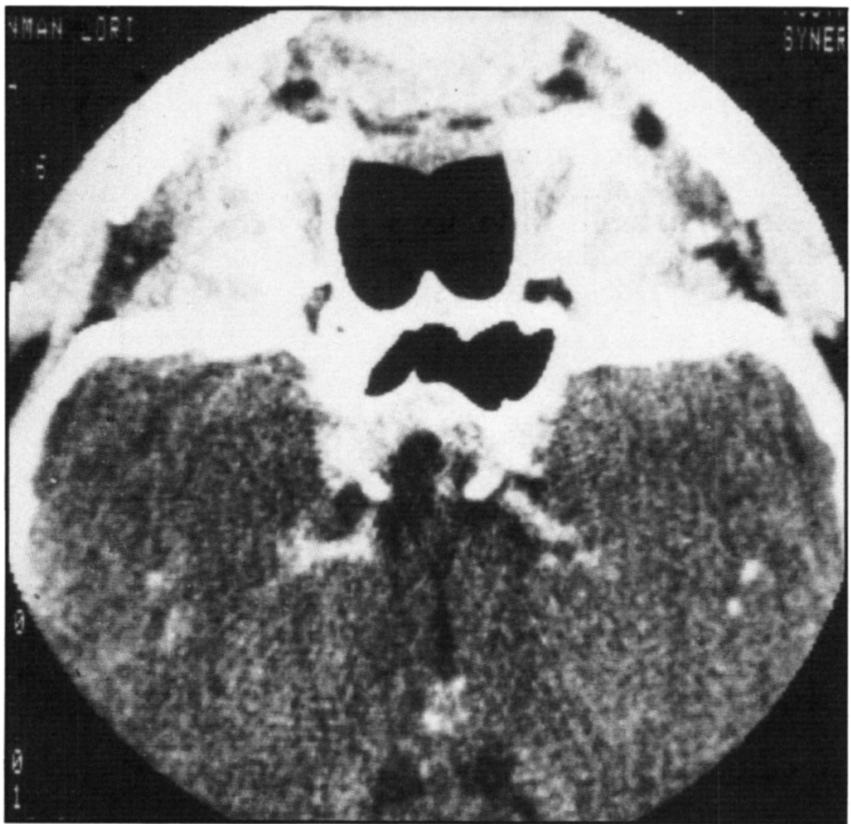

Figure Ib - Repeat CT scan one month after onset of bromocriptine therapy. Marked regression of the adenoma is demonstrated with production of a partial empty sella. showed no return of gonadal function despite normalization of serum prolactin following one year of bromocriptine therapy, or after the addition of clomiphene citrate.

Of the 41 women with normal sella turcicas, 40 demonstrated normal pituitary reserve and all 40 had return of menses, and 24 of 28 became pregnant. One patient with abnormal pituitary reserve failed to have return of menses, and demonstrated progressive hypothalamic insufficiency resulting from a granulomatous infiltrate which became evident after a follow-up over two years. A biopsy of the hypothalamus demonstrated histiocytosis.

Of the three patients with primary amenorrhea, two of the three showed marked regression in size of the mass, and all three spontaneous onset of menses (Fig. la and Fig. 1b).

Eighty-nine of these patients have been followed for at least five years without any long-term problems arising that were not obvious within the short-term institution of therapy.

Of the 16 males, eleven had macroadenomas, and five microadenomas (Table 3). The 11 men with macroadenomas included seven with suprasellar extension of the mass, six of whom had mass signs. Six demonstrated regression of the suprasellar extension. Of the five with abnormal visual fields, four were normalized. One patient, who did not demonstrate any regression of the mass or normalization of the visual fields, underwent surgery for removal of a cystic adenoma. Headaches improved in all nine with complaints of this. There was an increase of serum testosterone and improvement of decreased libido in 11 of the 16 men, while five required testosterone supplementation to continued bromocriptine therapy.

The group as a whole had normalization of the serum prolactin in 138 of 156 patients. Those that did not completely normalize, generally had an improvement in their gonadal status. All women with symptomatic galactorrhea had it markedly lessen or disappear so that it was no longer clinically significant. Four patients requested discontinuation of bromocriptine therapy after successful therapy for a minimum of one year, all because of cost or personal preference. No long-term complications of note occurred, although minor chronic nasal stuffiness was volunteered in 21 patients after direct questioning.

The twenty-six patients with acromegaly varied in age from 19 to 67 and included 16 females, six of whom had concomitant hyperprolactinemia, and two patients had the multiple endocrine adenomatosis syndrome. Nine were treated with bromocriptine as the primary form of therapy, ten following unsuccessful surgery, four following unsuccessful surgery and irradiation,

\section{Table 3: Response of 16 Men With Prolactinomas to Medical Therapy}

A. Macroadenomas $(n=11)$

Normalize visual field abnormalities $4(5)^{*}$

Decrease tumor size 10

Loss of headaches $7(8)$

Improved libido 8(11)

B. Microadenomas $(\mathrm{n}=5)$

Loss of headaches 2(3)

Improved libido $3(5)$

\footnotetext{
* Figure in brackets indicates number of patients with this symptom.
} 
and three following unsuccessful irradiation at least five years prior to the institution of bromocriptine therapy (Table 4). Clinical improvement was noted in 13 patients, which included decreased greasiness of the skin, decreased sweating, fewer headaches, more energy, onset of menses in amenorrheic women, regression of soft tissue swelling and symptoms of carpal tunnel syndrome, and improvement of diabetes mellitus. Of seven insulin-requiring diabetics, four clearly demonstrated decreased insulin requirements, but none discontinued insulin. Biochemical normalization of growth hormone was not noted in any patient, with partial normalization demonstrated in six, all measured after glucose administration. Clear decreases in tumor size were noted with CT scanning in two patients, both with concomitant hyperprolactinemia. None of the patients had any signs of an underlying mass at the time of onset of medical therapy. The bromocriptine failures subsequently underwent irradiation treatment, if this was not previously administered.

Five patients with Cushing's disease had primary treatment with cyproheptadine for a minimum of three months (Table 4). A biochemical remission with lessening of the clinical signs was noted in only one patient. This included normalization of the urinary free cortisol, and a normal response to insulin-induced hypoglycemia. This patient has remained on cyproheptadine and has undergone pituitary irradiation. The other four patients without any clinical or biochemical remission have subsequently undergone transphenoidal resection of the underlying pituitary adenoma. Two of these four normalized their biochemical parameters and the remaining two subsequently required bilateral adrenalectomy. The two patients with Nelson's syndrome both presented with invasive ACTH secreting pituitary adenomas. The first patient had this diagnosis for seventeen years, and had previously unsuccessful conventional irradiation and surgery. It response to the combination of cyproheptadine and bromocriptine, there was a decrease of the serum ACTH concentration, decreased clinical pigmentation, loss of headaches, less depression, and cessation of tumor growth that was previously documented to be progressing with repeated CT scanning. With discontinuation of the medication there was a return of headaches and definite tumor growth was visualized. With reintroduction of bromocriptine and cyproheptadine, she has again stabilized. The second patient had two previous unsuccessful

Table 4: Response of GH and ACTH Secreting Adenomas to Medical Therapy

\begin{tabular}{llc}
\hline \hline & Previous Therapy & $\begin{array}{c}\text { Clinical } \\
\text { Improvement }\end{array}$ \\
\hline A. Acromegaly & None & $6(9)^{*}$ \\
& Surgery & $4(10)$ \\
& Surgery + irradiation & $1(4)$ \\
& Irradiation & $2(3)$ \\
Total & & $13(26)$ \\
B. Cushing's disease & None & $1(5)$ \\
C. Nelson's syndrome & Surgery & $0(1)$ \\
& Surgery + irradiation & $0(1)$ \\
& Stabilize adenoma growth & $2(2)$ \\
\hline
\end{tabular}

* Figures in brackets indicate total number of patients in each category surgical resections, and pituitary irradiation eight years prior to therapy, with CT scan evidence of continued tumor growth. In response to sodium valproate for one year there has been loss of headaches and cessation of previously domumented tumor growth as shown by repeated CT scanning.

\section{Discussion}

Pituitary adenomas may have local effects, but if there is hypersecretion of a hormone, then there may be significant metabolic and cosmetic effects, especially seen in Cushing's disease and acromegaly. These metabolic effects may decrease longevity, mainly through cardiovascular manifestations. Hyperprolactinemia may result in hypogonadism with possible long-term problems such as osteoporosis, but generally longevity is not affected. It is for these differences in prognosis that ablative therapy with surgery and/or irradiation is generally the treatment of choice for Cushing's disease and acromegaly, whereas invasive therapy or medical therapy may be individualized for any given patient with a prolactin-secreting pituitary adenoma. Because medical therapy is not curative for Cushing's disease or acromegaly and tumor regression only occasionally occurs, medical therapy remains as an adjunct. Medical therapy may be used to prepare a patient for surgery, for cases of failed ablative therapy, or for the elderly patient. Prolactin-secreting adenomas appear to do well both with dopamine agonists and with surgery, and even though medical therapy is not curative, tumor regression is almost expected for the large adenomas. There are reports of spontaneous "cure" following bromocriptineinduced pregnancies and two such cases are in this reported series. Because long-term follow-up of surgical results may have a recurrence of $15 \%$ (Faglia et al 1983) to 55\% (Serri et al 1983), there may not be a long-term major advantage over medical therapy, especially since the disorder does not have major metabolic complications, but rather results in reversible hypogonadism. Only infrequently are there problems with progressive tumor growth or apoplexy (Breidahl et al 1983).

The control of prolactin is unique in the pituitary gland, as it is predominately under inhibitory control. Bromocriptine was developed as a dopamine agonist, and will normalize prolactin in $80-90 \%$ of patients with pituitary adenomas (Friesen and Tolis 1977), with resulting reversal of associated hypogonadism and galactorrhea. Bromocriptine is absorbed orally and reaches a maximum blood level after 90 minutes, but the maximum effect on suppression of prolactin secretion occurs several hours later. The initial side effects of nausea and light-headedness may be minimized by beginning with a small dose taken with meals or at bedtime, and building up over two or three weeks. Chronic symptoms may include nasal stuffiness, Raynaud's syndrome, and constipation. Neuropsychiatric abnormalities usually occur only with high doses such as seen with the treatment of Parkinsonism, but may rarely occur with low doses. Indications for therapy are infertility, arrested or delayed puberty, galactorrhea, decreased libido, presence of a tumor mass, return of estrogenization or androgenization status, and to inhibit the progression of osteopenia. Bromocriptine does not appear to be teratogenic (Turkal et al 1982). It appears that bromocriptine decreases prolactin secretion initially by inhibiting exocytotic events, and later by decreasing intracellular prolactin content, which infers decreased synthesis. The regression of tumor size was first noted in animals, and later in humans (Corenblum et 
al 1975). The decrease in size of the mass appears to result in part from decreased cell volume (Tindall et al 1982) without any net cell loss, and appears to be reversible. There is a regularly observed decrease in the size of large adenomas with suprasellar extension (Corenblum and Hanley 1981) that are rarely cured with surgery. The long-term effects of bromocriptine on tumor size have yet to be reported over a large series, but this study appears to support that initial regression in size is maintained with continued bromocriptine therapy for up to ten years. It has been suggested that therapy for more than one year results in fibrosis of the tumor resulting in more difficult tumor removal at the time of surgery (Landolt et al 1982), while short term therapy with bromocriptine may improve surgical results, presumably by producing regression of tumor size. Another report failed to find that previous bromocriptine therapy had any worsening of the success rate of surgery (Faglia et al 1983).

Other dopamine agonists such as pergolide appear to be very similar to bromocriptine and have the advantage of being longer acting, or producing a response in patients who are otherwise resistant or intolerant to bromocriptine (Franks et al 1983). Decreased tumor size has also been seen with other dopaminergic agonists (Kendall-Taylor et al 1982). Tamoxifen, an estrogen receptor antagonist, has been used to decrease prolactin when added to bromocriptine with patients resistant to bromocriptine alone (Volker et al 1982).

Metergoline has been used as a serotonin antagonist, although it has some intrinsic dopamine agonist activity. It may improve the clinical and biochemical abnormalities in hyperprolactinemic patients, but appears to have similar side effects as bromocriptine without the same predictable results, and thus does not have any real advantage.

It is the author's opinion that large prolactin-secreting pituitary tumors generally have an unsatisfactory response to surgery, in that rarely is the patient rendered endocrinologically normal, the frequency of hypopituitarism is relatively high, and the success rate of total tumor removal is low. In such patients, pituitary irradiation is too slow to adequately treat extrasellar complications. For this reason, bromocriptine is probably the treatment of choice and if no response to medical therapy for six months is demonstrated, including regression of mass signs, surgical therapy may then be performed. Tumor regression is usually apparent in 2 - 4 weeks, so a short trial is probably informative, but in some cases it takes several months to see tumor regression. The fear that the pituitary tumor may continue to grow despite successful decrease of symptoms of hyperprolactinemia with bromocriptine is more theoretical than real, although there have been occasional reports of pituitary tumor growth despite continued bromocriptine therapy (Breidahl et al 1983). The author has never observed such an occurrence, nor a microadenoma enlarging to be classified as a macroadenoma. Tumor growth may occur during a pregnancy if the bromocriptine has been discontinued, but regresses with reinstitution of the drug.

The treatment of choice for acromegaly remains as ablative therapy, either surgery or irradiation, with the use of bromocriptine as an adjuvant.

Supervoltage external irradiation is usually successful, hut may take many years, and has a problem of hypopituitarism and possibly some progressive visual failure (Atkinson et al 1979). Neural damage appears to be related to the dose, and inversely related to the number of treatments, so presently 4,500 to 5,000 rads are administered in 20 - 25 fractions over 35 days.

The paradoxical response to dopamine in suppressing growth hormone and TRH in stimulating growth hormone, in patients with acromegaly, appears to be due to a direct effect of these drugs on the pituitary tumor, based on in vitro studies, as well as by the direct effect of a dopamine infusion in decreasing growth hormone. Furthermore, these qualitatively abnormal responses disappear after successful surgery. It is possible that there is a common stem cell for both prolactin and growth hormone cells, and growth hormone secreting adenomas may represent a dedifferentiation to a common cell type. The suppressive effects of bromocriptine on growth hormone secretion in patients with acromegaly are shorter in duration that that seen with prolactin adenomas. For this reason, bromocriptine should be administered four times a day for the treatment of acromegaly, as opposed to twice for prolactin adenomas. Furthermore, the dosage in acromegaly is higher than with prolactin adenomas, averaging about $20 \mathrm{mg}$ per day, but occasionally reaching up to $60 \mathrm{mg}$ per day. These doses give rise to more common side effects, including hypotension, nausea, constipation, dryness of the mouth, digital vasospasm, and nasal stuffiness. Such problems may be present in about one-third of patients and occasionally may require discontinuation of the medication. Bromocriptine restores serum growth hormone levels to normal in only a minority of patients, yet clinical improvement is frequently observed, one study showing an improvement in 97\% (Wass et al 1977). Clinical indices of improvement are a decrease in hand, foot, and ring size, decreased sweating, loss of headaches, improved libido, and improved glucose tolerance. In one study, glucose intolerance became normal in $65 \%$ of patients (Wass et al 1977). The clinical improvement has been noted in repeated studies (Wass et al 1983), despite the frequent failure to normalize serum growth hormone concentrations. It has been postulated that bromocriptine preferentially decreases the biologically active growth hormone, the monomeric fraction. It is also postulated that there is a peripheral action in decreasing somatomedin generation without any change in growth hormone levels (Wass et al 1983). It was initially thought that only the acromegalics who acutely suppressed with bromocriptine or released hormone to TRH would respond to long-term bromocriptine therapy, but recent follow-up has shown that over $75 \%$ of all patients demonstrate a clinical response. Clinical observations have noted that patients are more likely to respond if there is concomitant hypersecretion of prolactin, indicating a mixed adenoma (Corenblum et al 1976). There have been reports of regression of tumor size (Atkinson et al 1979) usually in patients with concomitant hyperprolactinemia, and this study is consistent with those observations.

The role of bromocriptine for the treatment of acromegaly is to complement patients treated with external irradiation, or in patients who are surgical failures, but may be considered as primary therapy in elderly patients, or in other selected patients. For this reason with any patients that demonstrate a clinical response to bromocriptine used as the primary form of therapy, we recommend a course of external irradiation while the patient is maintained on the bromocriptine.

ACTH secreting pituitary tumors remain the most complicated to treat, as well as the most important, due to significant peripheral metabolic complications along with potential central neurological 
complications due to tumor growth. Small adenomas respond to transphenoidal microsurgical resection and this remains the treatment of choice. Should this be unsuccessful, or should the underlying pituitary abnormality be hyperplasia as opposed to adenoma, then either bilateral adrenalectomy or medical therapy along with external irradiation should be considered. Several neuropharmacological agents have been utilized, all based on the multitude of neurotransmitters known to effect ACTH secretion. Agents which affect adrenal synthesis of cortisol, such as metyrapone, aminoglutethimide, and the adrenolytic drug $0, p-D D D$ have all been utilized to prepare the patient for surgery, or to await results of irradiation. A complication of bilateral adrenalectomy is continued growth of an ACTH secreting tumor, Nelson's syndrome. Prophylactic pituitary irradiation is usually recommended, and this may decrease the incidence, but may not entirely prevent the occurrence of Nelson's syndrome (Moore et al 1976). Cushing's disease may result from an ACTH secreting pituitary adenoma or corticotroph hyperplasia. This may result from either inappropriate secretion of corticotropin-releasing hormone or else autonomous secretion by the corticotrophs, or possibly some inter-relation between these two factors. There is experimental evidence to suggest that serotonin and acetylcholine facilitate the release of corticotropin-releasing hormone. Cyproheptadine has antiserotonergic and anti-cholinergic activities, and has been shown to blunt the enhanced ACTH secretion that occurs in response to hypoglycemia (Plonk et al 1974), and metyrapone (Plonk et al 1976). Cyproheptadine does not appear to have any direct action on ACTH secretion in dispersed pituitary cells, but may have this action in adenomatous cells, and this effect may be abolished with the addition of serotonin (Ishibashi and Yamaji 1981). In approximately 100 patients, remission of Cushing's disease occurred in $35-50 \%$ (Krieger 1983), and the longest reported successful therapy is up to five years. Patients who respond generally show a clinical and laboratory remission in two to three months of therapy, and remission for up to three years after discontinuing cyproheptadine has been reported. Unfortunately, relapse invariably occurs, occasionally while still receiving cyproheptadine. The utilization of cyproheptadine and irradiation therapy has allowed cyproheptadine to be discontinued within four months, with continued clinical remission. Unfortunately, there are also many unsuccessful reports of therapy with cyproheptadine, and the author's small experience finds the beneficial response is noted in a minority of patients. The side effects of therapy include somnolence and hyperphagia and appears to be most marked in children. Along with a clinical remission, there is usually a return of normal biochemical parameters. This includes a return of normal diurnal rhythm, normal serum and urinary cortisol concentrations, and a return of normal suppression with administration of dexamethasone. Women may notice return of normal menses, lessening of hirsutism, loss of weight, and decreased facial rubor. Psychiatric manifestations may lessen. Cortisol concentrations begin to decrease in about two months, with clinical remission occurring in four to six months, and return of normal cortisol secretory dynamics in about six months.

The utilization of bromocriptine has its origin in the observation that dopamine may be inhibitory to the secretion of ACTH. Such patients may possibly be selected by the administration of bromocriptine (Lamberts et al 1982), and it has been suggested that such responsive adenomas or hyperplasia arise in the intermediate area of the pituitary where direct innervation of corticotrophs may occur from dopaminergic fibres. A small series has found that bromocriptine will improve the clinical and biochemical manifestations of Cushing's disease in six of 13 patients, but it may not be long maintained (Lamberts et al 1980). We have used bromocriptine for at least three months in four patients with Cushing's disease without any clinical or biochemical response.

GABA appears to decrease corticotropin-releasing hormone secretion (Jones et al 1976), and may be involved in the cortisol feedback action (Avs and Stark 1978). Sodium valproate decreases GABA transaminase which will increase GABA biological activity. Furthermore, sodium valproate may also have an affect on the post-synaptic GABA receptor, and again enhance GABA biological activity. Published reports find sodium valproate improving some cases with Cushing's disease (Koppeschaar et al 1982), but not others (Allolio et al 1982). One case reported was of a response to both cyproheptadine and valproate (Koppeschaar et al 1983). In ten patients with Nelson's syndrome, ACTH concentrations have decreased in response to sodium valproate (Dornhorst et al 1983). Tumor regression may occur in that loss of headaches and diabetes insipidus have been reported (Elras et al 1981; Jones et al 1981). Most reports to date are preliminary and continue to have the problem of unpredictability of response.

The opioid antagonist naloxone has been shown to decrease ACTH secretion in Nelson's syndrome (Tolis et al 1982), but long acting opioid antagonists have yet to be utilized in clinical trials.

It appears that only a minority of patients with ACTH secreting pituitary tumors respond to medical therapy, and these patients cannot be predicted. The response does not appear to be related to the size of the tumor, not to the severity of the clinical symptoms. Due to the side effects and inconsistency of response, neuropharmacological agents remain as the second line of therapy, as an adjunct to radiotherapy, in failed surgical therapy, or to prepare a patient for surgery.

We have not had any experience with primary TSH secreting adenomas, but one report indicates that dopaminergic agents such as L-dopa and bromocriptine may be useful (Horn et al 1976). In both TSH secreting tumors and FSH secreting tumors related to long-standing primary target gland failure, there has been regression of both size and secretion of these adenomas in response to replacement of the feedback hormone. Three such cases have been treated in this centre, but are not reported in this study. Non-secreting pituitary tumors have had either isolated reports (Johnston et al 1981), as well as a series of cases responding to bromocriptine (Wollesen et al 1982). These studies have demonstrated decreased size of non-secreting pituitary tumors, but the decrease does not appear to be as rapid as what is seen with prolactinomas. Furthermore, they may need to be treated for at least one year to see any radiological improvement. We do not have any experience in treating nonsecreting pituitary tumors wish neuropharmacological agents, and ablative therapy remains the treatment of choice, if clinically indicated. Because some of these tumors may be prolactinomas that are not releasing the synthesized hormone, a trial of bromocriptine when ablative therapy fails may be attempted. Immunostaining of any surgically removed tissue for prolactin may be useful to predict such a response.

In summary, the utilization of neuropharmacological agents 
based on neurotransmitter physiology has been utilized to treat the hypersecretory state and tumor growth of pituitary adenomas. Present indications vary from the first line treatment of choice for both prolactin secreting macroadenomas and probably microadenomas, and as adjuncts to ablative therapy for treatment of acromegaly and ACTH secreting pituitary adenomas.

\section{REFERENCES}

Acs Z, Stark E (1978) Possible role of gamma-aminobutyric acid synthesis in the mechanism of dexamethasone feedback action. J Endocrinol 77: 137-141.

Allolio B, Winkelmann W, Laulen D, Hipp FX, Mies R (1982) Valproate in Cushing's syndrome. Lancet $1: 171$.

Atkinson AB, Allen IV, Gordon DS, Hadden DR, Maguire CJF, Trimble ER, Lyons AR (1979) Progressive visual failure in acromegaly following external pituitary irradiation. Clin Endocrinol 10:469-479.

Breidah! HD, Topliss DJ, Pike JW (1983). Failure of bromocriptine to maintain reduction in size of a macroprolactinoma. $\mathrm{Br}$ Med $\mathbf{J} 287$ : 451-452.

Burrow GN, Wortzman G, Rewcastle NB, Holgate RC, Kovacs K (1981) Microadenomas of the pituitary and abnormal sellar tomograms in an unselected autopsy series. N Engl J Med 304: 156-158.

Chiodini PG, Liuzzi A, Botalla G, Cremascoli G, Silvestrini F (1974) Inhibitory effect of dopaminergic stimulation on $\mathrm{GH}$ release in acromegaly. J Clin Endocrinol Metab 38: 200-206.

Corenblum B, Webster BR, Mortimer CB, Erzin C (1975) Possible anti-tumor effect of 2-bromo-ergocryptine in two patients with large prolactin-secreting pituitary tumors. Clin Res 23: 614 .

Corenblum B, Sirek AMT, Horvath E, Kovacs K, Erzin C (1976) Human mixed somatotrophic and lactotrophic pituitary adenomas. J Clin Endocrinol Metab 42: 857-863.

Corenblum B (1979) Role of dynamic pituitary testing in patients with hyperprolactinemia. Diagn Gynecol Obstet 1: 153-164.

Corenblum B, Hanley DA (1981) Bromocriptine reduction of prolactinoma size. Fertil Steril 36: 716-719.

Corenblum B, Taylor PJ (1983) Long-term follow-up of hyperprolactinemic women treated with bromocriptine. Fertil Steril 40: 596-599.

Costello RT (1936). Subclinical adenoma of the pituitary gland. Am J Pathol 12: 205-215.

Dornhorst A, Jenkins JS, Lamberts SWJ, Abraham RR, Wynn V, Beckford U, Gillham B, Jones MT (1983) The evaluation of sodium valproate in the treatment of Nelson's syndrome. J Clin Endocrinol Metab, 56: 985-991.

Elias AN, Gwinup G, Valenta LJ (1981) Effects of valproic acid naloxone, and hydrocortisone in Nelson's syndrome and Cushing's disease. Clin Endocrinol 15: 151-154.

Faglia G, Moriondo P, Travaglini P, Giovanelli MA (1973) Influence of previous bromocriptine therapy on surgery for microprolactinoma. Lancet 1: 133-134.

Franks S, Horrocks PM, Lynch SS, Butt WR, London DR (1983) Effectiveness of pergoline mesylate in long term treatment of hyperprolactinaemia. Br Med J 286: 1177-1179.

Friesen HG, Tolis G (1977) The use of bromocriptine in the galactorrheaamenorrhea syndrome: the Canadian cooperative study. Clin Endocrinol 6 (Suppl) 91-99.

Horn K, Erhardt F, Fahlbusch R, Pickardt CR, Weder K, Scriba PC (1976) Recurrent goiter, hyperthyroidism, galactorrhea and amenorrhea due to a thyrotropin and prolactin-producing pituitary tumor. J Clin Endocrinol Metab 43: 137-143.

Ishibashi M, Yamaji T (1981) Direct effects of thyrotropin-releasing hormone, cyproheptadine, and dopamine on adrenocorticotropin secretion from human corticotroph adenoma cells in vitro. J Clin Invest $68:$ 1018-1027.

Johnston DG, McGregor A, Ross WM, Hall R (1981) Bromocriptine therapy for "non-functioning" pituitary tumors. Am J Med 71: 1051-1061.
Jones MT, Hillhouse EW, Burden J (1976) Effect of various putative neurotransmitters on the secretion of corticotrophin-releasing hormone from the rat hypothalamus in vitro - a model of the neurotransmitters involved. J Endocrinol 69, 1-10.

Jones MT, Gillam B, DiRenzo G, Beckford U, Holmes MC (1981). Neural control of corticotrophin secretion. Front Horm Res 8: 12-43.

Kendall-Taylor P, Hall K, Johnston, DG, Prescott RWG (1982) Reduction in size of prolactin-secreting tumors in men treated with pergolide. Br Med J 285: 465-467.

Koppeschaar HPF, Croughs RJM, Thijssen JHH, Schwarz F (1982) Sodium valproate and heterogeneity of the pituitary dependent Cushing's syndrome. Lancet 1: 1253.

Koppeschaar HPF, Croughs RJM, Thijssen JHH, Scwartz F (1983) Sodium valproate and cyproheptadine may independently induce remission in the same patient with Cushing's disease. Acta Endocrinol 104: 160-163.

Krieger DT (1983) Physiopathology of Cushing's disease. Endocrine Rev 4: 22-43.

Lamberts SWJ, Klijn JGM, de Quijada M, Timmermans HAT, Uitterlinden P, de Jong FH, Birkenhager JC (1980) The mechanism of the suppressive action of bromocriptine on adrenocorticotropin secretion in patients with Cushing's disease and Nelson's syndrome. J Clin Endocrinol Metab. 51: 307-311.

Lamberts SWJ, de Lange SA, Stefanko SZ (1982) Adrenocorticotropinsecreting pituitary adenomas originate from the anterior or the intermediate lobe in Cushing's disease: differences in the regulation of hormone secretion. J Clin Endocrinol Metab 54: 286-291.

Landolt AM, Kellar PJ, Froesch ER, Mueller J (1982) Bromocriptine: does it jeopardise the result of later surgery for prolactinomas? Lancet 3: 657-658.

Moore TJ, Dluhy RG, Williams GH, Cain JP( 1976) Nelson's syndrome: frequency, prognosis, and effect of prior pituitary irradiation. Annals Int Med 85: 731-734.

Plonk JW, Bivens CH, Feldman JH (1974) Inhibition of hypoglycemiainduced cortisol secretion by the serotonin antagonist cyproheptadine. J Clin Endocrinol Metab 38: 836-840.

Plonk J, Feldman JM (1976) Modification of adrenal function by the antiserotonin agent cyproheptadine. J Clin Endocrinol Metab 42: 291-295.

Serri O, Radio E, Beauregard H, Hardy J, Somma M (1983) Recurrence of hyperprolactinemia after selective transsphenoidal adenectomy inwomen with prolactinoma. N Engl J Med 309: 280-283.

Stubbs WA, Delitala G, Jones A, Jeffcoate WJ, Edwards CRW, Rees LH, Besser GM (1978) Hormonal and metabolic responses to an enkephalin analogue in normal man. Lancet 4: 1225-1227.

Tindall GT, Kovacs K, Horvath E, Thorner MO (1982) Human prolactinproducing adenomas and bromocriptine: a histological, immunocytochemical, ultrastructural, and morphometric study. J Clin Endocrinol Metab 55: 1178-1183.

Tolis G, Juckier L, Wiesen M, Krieger DT (1982) Effect of naloxone on pituitary hypersecretory syndromes. J Clin Endocrinol Metab 54 780-784.

Turkal I, Braun P, Krupp P (1982) Surveillance of bromocriptine in pregnancy. JAMA 247: 1589-1591.

Volker W, Gehring WG, Berning R, Schmidt RC, Schneider J, Von Zur Muhlen A (1982) Impaired pituitary response to bromocriptine suppression: reversal after bromocriptine plus tomoxifen. Acta Endocrinol 101: 491-500.

Wass JAH, Thorner MO, Morris DV, Rees LH, Mason AS, Jones AE, Besser GM (1977) Long-term treatment of acromegaly with bromocriptine. Br Med J 1: 875-878.

Wass JAH, Clemmons DR, Underwood LE, Barrow I, Besser GM Van Wyk JJ (1982) Changes in circulating somatomedin-C levels in bromocriptine-treated acromegaly. Clin Endocrinol 17: 369-377.

Nass JAH, Besser GM (1983) The medical management of hormonesecreting tumors of the pituitary. Ann Rev Med 34: 283-294.

Wollesen F, Anderson T, Karle A (1982) Size reduction of extrasellar pituitary tumors during bromocriptine treatment. Annals Int Med 96: $281-286$ 